\title{
Elucidation of the liver proteome in response to an antioxidant intake in rabbits
}

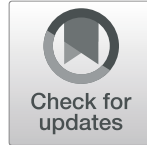

\author{
Akeem Babatunde Sikiru ${ }^{1,2}$, Arunachalam Arangasamy ${ }^{2 *}$, Stephen Sunday Acheneje Egena', Sejian Veerasamy ${ }^{3}$, \\ Ippala Janardhan Reddy ${ }^{3}$ and Bhatta Raghavendra ${ }^{4}$
}

\begin{abstract}
Background: Antioxidant intakes are one of the most cherished dietary approaches for the management of oxidative stress-induced liver damages. These antioxidants exist as the bioactive compounds present in plants and other natural sources functioning in varieties of ways from acting as direct scavengers of the free radicals to acting as the modifiers of genes and proteins expressions. Chlorella vulgaris is one of such antioxidants; it is a unicellular microalga and a rich source of polyphenols which has been reported for its capacity of reducing oxidative stress by upregulation of antioxidant genes. However, there are scarce reports on its effect on antioxidant protein expressions and functions in the liver. This situation necessitates untargeted proteomic profiling of the liver due to the antioxidant intakes as carried out in this present study. Sixteen laboratory weaner rabbits of 8 weeks old with initial average bodyweight of $1060 \pm 29.42 \mathrm{~g}$ were randomly divided into two groups ( $n=8$ per group); the first group served as control while the second served as the treatment group were used for this study.

Results: After a period of 120 days daily consumption of $500 \mathrm{mg}$ of Chlorella vulgaris biomass per kg bodyweight of the rabbit models, the animals were sacrificed and their livers were harvested followed by protein extraction for the untargeted proteomic profiling using LC-MS/Orbitrap Fusion Tribrid ${ }^{\mathrm{TM}}$ peptides quantifier and sequencer. Also, there was an assessment of the oxidative stress biomarkers in the liver and serum of the rabbits. Five-hundred and forty-four (544) proteins were identified out of which 204 were unique to the control, 198 were unique to the treatment group, while 142 were common to both groups of the rabbits. Antioxidant proteins commonly found in both groups were upregulated in the treatment group and were significantly associated with oxidative stressprotective activities. There was a reduction in oxidative stress biomarkers of the supplemented group as indicated by the assessment of the liver malondialdehyde concentrations $(p<0.05)$, total antioxidant capacities $(p<0.05)$, and antioxidant enzyme activities $(p<0.05)$. Similarly, these biomarkers were significantly reduced in the serum of the supplemented rabbits $(p<0.05)$.

Conclusion: The study concluded that Chlorella vulgaris is an antioxidant agent that could be suitable for reducing liver oxidative stress damage and it is a potential drug candidate for protecting the liver against oxidative stress damages as revealed in the rabbit models.
\end{abstract}

Keywords: Oxidative stress, Chlorella vulgaris, LC-MS, Malondialdehyde, Liver Proteins, Rabbits

\footnotetext{
* Correspondence: arangasamyars@gmail.com

${ }^{2}$ Reproductive Physiology Laboratory, ICAR-National Institute of Animal

Nutrition and Physiology, Bangalore 560030, India

Full list of author information is available at the end of the article
}

\section{Springer Open}

(- The Author(s). 2021 Open Access This article is licensed under a Creative Commons Attribution 4.0 International License, which permits use, sharing, adaptation, distribution and reproduction in any medium or format, as long as you give appropriate credit to the original author(s) and the source, provide a link to the Creative Commons licence, and indicate if changes were made. The images or other third party material in this article are included in the article's Creative Commons licence, unless indicated otherwise in a credit line to the material. If material is not included in the article's Creative Commons licence and your intended use is not permitted by statutory regulation or exceeds the permitted use, you will need to obtain permission directly from the copyright holder. To view a copy of this licence, visit http://creativecommons.org/licenses/by/4.0/. 


\section{Background}

Oxidative stress is a physiological and biochemical compromise affecting animal and human performances. It triggers damages of the liver by inducing irretrievable alteration of the lipids, proteins, and DNA contents of the liver as well as modulation of pathways associated with the control of normal biological functions of the liver $[1,2]$. Therefore, to overcome these negative impacts of oxidative stress for the benefits of animals and human well-being, the intake of antioxidant-rich dietary supplements is a necessity. Microalgae are examples of such resources and previous studies have demonstrated the antioxidant efficacies of different types of microalgae among which is the microalga Chlorella vulgaris. The microalga Chlorella vulgaris is one of the most common microalgae suggested as a critical functional food and or feeds for humans and animals because of its rich protein, vitamins, and minerals [3].

According to Christaki et al. [4], microalgae generally can be considered as sources of minerals and complementary sources of protein and functional nutrients that are suitable for use in both animals and humans. Chlorella vulgaris as a functional food for humans, in addition to its regular nutritional composition of protein, carbohydrates, vitamins, and minerals, can provide healthpromoting benefits such as immune activation, antioxidant, anticarcinogenic, and also serving as an antitoxic agent [5]. In a bid to facilitate the understanding of the mechanisms of the antioxidant properties of the microalga Chlorella vulgaris, its effects on patterns of gene expression in rabbit models have been investigated and it was discovered to be capable of inhibiting the progression of oxidative stress via upregulation of antioxidant genes in the liver of rabbits [6]. However, there are scarce reports on its effect on antioxidant proteins expression in the liver of rabbits; meanwhile, this is important because untargeted proteomic profiling is an approach suitable for the assessment of how effective is a gene code translated into the relevant polypeptide chains folded into functional proteins desirable for specific sub-cellular or extracellular physiological activities [7]. It remains one of the most required comparative avenues that could be used for evaluation and validation of the efficacies of supplement and nutraceutical agents including antioxidants.

For the management of liver-specific performance dysfunctions, it is highly critical to identify natural sources of an antioxidant such as microalgae to serve as dietary supplements as these could be cheap means of alleviating liver damage-related deaths across the world [1]. The alleviation of liver-associated diseases could mean the promotion of human well-being because these diseases were reported to be responsible for the cause of approximately 2 million deaths per year across the world which are shared equally between complications of cirrhosis and viral hepatitis cum hepatocellular carcinoma, and non-alcoholic fatty liver diseases (NAFLD) [8]. However, these complications have close relationships with oxidative stress and this necessitates critical research for potential antioxidant drug candidates [9].

The microalga Chlorella vulgaris is an antioxidant agent with confirmed capacity of oxidative stress in inhibition at different physiological reproductive stages in rabbit models with specific oxidative stress protection for the liver [5, 10-12]. The microalga supplementation in fishes and other models was also reported and all the evaluations concluded that the microalga modulates the regulation and expression of primary antioxidant genes as mechanisms associated with its oxidative stress protection [13]. These submissions necessitate investigating the effect of the microalga on patterns of antioxidant protein expression in the liver considering its potential in the prevention and management of critical oxidative stress-induced liver diseases. This is the background on which this present study was carried out because proteins are critical to normal physiological functions since they are the biomolecules enabling genes to perform their functions in an organism. Hence, this present study hypothesized that for adequate protection against oxidative stress in the liver by Chlorella vulgaris it should be capable of increasing expression of proteins that are specific for the enhancement of the free radicals scavenging.

The production of these antioxidant proteins can also be used as an indicator for determining the posttranslation impacts of antioxidant agents on gene expression modulation [14]. Furthermore, the process of quantifying and identification of these proteins associated with antioxidant agent supplementation could also serve as a novel approach for tracking and understanding the oxidative stress attenuation capacity of antioxidant agents such as Chlorella vulgaris [15]. However, to our knowledge, the effect of Chlorella vulgaris supplementation on the abundance of the hepatic proteome in connection with oxidative stress biomarkers in rabbits have not been reported. Therefore, the study focused on the identification and understanding of the proteins, processes, and pathways associated with oxidative stress in the liver of rabbits.

\section{Methods}

\section{Experimental protocol and animal ethics approval}

Sixteen laboratory rabbits sourced from the Laboratory Animal Facilities of Biogen Biotechnology (P) Ltd., Bangalore, India. The animals were used for this study and the approval for use of the animals and the implementation of the experimental protocols was obtained from a joint sitting of the Institutional Animal Ethics 
Committee (IAEC) of National Institute of Animal Nutrition and Physiology, India, and Committee for Control and Supervision on Experiments on Animals (CPCSEA), India. The animals were divided into two experimental groups ( $n=8$ per group); the first group served as control while the second served as the treatment group. The rabbits in both groups were fed ad-libitum with commercial rabbit feed (Krishna Valley Agrotech (P) Ltd., India) as daily basal feeds. In addition to the basal feeds, rabbits in the treatment group were supplemented with $500 \mathrm{mg}$ Chlorella vulgaris biomass per kg body weight daily for the period of 120 days. Water was also supplied ad libitum through automatic nipple drinkers, while the rabbits were housed individually in hutches.

\section{Samples preparation and protein extraction Sample collection and storage}

The rabbits were selected one after the other for cervical dislocation to make them unconscious; the blood was collected exsanguination followed by the removal of the livers of each rabbit and kept in a cold phosphate buffer $\mathrm{pH} 7.4$ then stored in a refrigerator ahead of downstream proteomics profiling at $-80{ }^{\circ} \mathrm{C}$ (Thermo Fisher Scientific, India). Blood was collected for serum harvest by allowing the blood to coagulate at room temperature followed by centrifugation at $3500 \mathrm{rpm}$ for $15 \mathrm{~min}$ (NEYA Centrifuge, India).

\section{Quantification of the liver protein concentrations}

Homogenates of each liver were prepared and the total protein concentration in each sample was determined using a commercial protein quantification kit (Arkray Healthcare (P) Ltd., India). The kit assay principle involves the reaction of protein with cupric ions in alkaline solutions to form colored chelate whose absorbance was measured at $578 \mathrm{~nm}$. The assay is composed of Biuret reagent including copper sulfate (7 $\mathrm{mmol} / \mathrm{L})$, sodium hydroxide $(200 \mathrm{mmol} / \mathrm{L})$, sodiumpotassium tartrate $(20 \mathrm{mmol} / \mathrm{L})$, and a surfactant. Bovine serum albumin was used as standard and the reaction mixtures were incubated at $37{ }^{\circ} \mathrm{C}$ for $5 \mathrm{~min}$ before the absorbance measurement using a Thermo Multiskan GO microplate reader (Thermo Fisher Scientific, Finland).

\section{Determination of oxidative stress biomarkers}

Oxidative stress biomarkers including the malondialdehyde, protein carbonyl contents, total antioxidant capacity, and antioxidant enzyme activities of the liver and serum were determined using chemical assays as described in our previous studies [5].

Proteomic profiling: protein extraction, precipitation, digestion, and quantification

\section{Protein extraction}

There was protein extraction from the liver of the rabbits using the radioimmunoprecipitation assay (RIPA) buffer made up of $25 \mathrm{mmol}$ Tris $\mathrm{HCl}$ (pH 7.6), 150 mmol sodium chloride $(\mathrm{NaCl}), 1 \%$ nonyl phenoxypolyethoxylethanol-40 (NP-40), and $0.1 \%$ sodium dodecyl sulfate (SDS). Simply, the procedures involve washing of the liver samples earlier stored at $-80{ }^{\circ} \mathrm{C}$ in phosphate buffer ( $\mathrm{pH}$ 7.4) after being thawed overnight at $4{ }^{\circ} \mathrm{C}$. Then for each of the samples, $100 \mathrm{mg}$ of the liver was sampled, and lysed under liquid nitrogen after which they were homogenized for $1 \mathrm{~min}$ then sonicated for 80 $\mathrm{s}$ in 4 strokes of $15 \mathrm{~s}$ each at 5-s interval (Thermocube, SScooling Systems; USA). The samples after sonication were centrifuged at $10,000 \mathrm{rpm}$ at $4{ }^{\circ} \mathrm{C}$ for $10 \mathrm{~min}$ (REMI microfuge, India) and the supernatants were collected then stored at $-80{ }^{\circ} \mathrm{C}$ ahead of the downstream proteomic analysis.

\section{Protein precipitation, digestion, and desalting}

There was a sampling of $20 \mu \mathrm{g}$ protein for precipitation in acetone overnight then centrifuge at $10,000 \mathrm{rpm}$ (REMI Microfuge, India). Then the precipitated protein samples were dissolved in $25 \mathrm{mmol}$ ammonium bicarbonate for the analysis. The analysis commenced with the addition of $100 \mathrm{mmol}$ of DTT (dithiothreitol) then incubated at $37{ }^{\circ} \mathrm{C}$ for $30 \mathrm{~min}$. After the incubation, there was an addition of 100 mmol IAA (Iodoacetamide) to obtain a concentration of $30 \mathrm{mmol}$ in the solution and kept in dark for $30 \mathrm{~min}$ after which the $\mathrm{pH}$ of the solution was adjusted to 8 by adding $25 \mathrm{mmol}$ ammonium bicarbonate. This was followed by digestion in trypsin $(0.2 \mu \mathrm{g} / \mu \mathrm{L})$ at a concentration of 1:50 trypsin: proteins; and after the trypsin digestion, the samples were incubated overnight at $37{ }^{\circ} \mathrm{C}$. Formic acid with a final concentration of $0.1 \%$ was then added to stop the reaction. The digested protein samples were desalted using $3 \times$ of $100 \%$ Acetonitrile and $3 \times$ of $0.1 \%$ formic acid then passed through a mini-column which wets the resin and conditioned to bind peptides from the protein samples. The column used was an ion exchange minicolumn while buffers including $0.1 \%$ formic acid in high-performance liquid chromatography (HPLC) water and $80 \%$ Acetonitrile $+0.1 \%$ formic acid in HPLC water were used as fundamental mobile phase solvents.

\section{Protein sequencing and LC-MS quantification}

For the peptides quantification, $1 \mu \mathrm{L}$ of the digested samples were used for liquid chromatography-mass spectrometry (LC-MS) quantification of the peptides in the protein samples using LC Model EASY nLC 1200 (Thermo Fisher Scientific, USA), with nanoflow rate 300 $\mathrm{nL} / \mathrm{min}$ and the protein sequencing was done using Orbitrap Fusion Tribrid $^{\mathrm{ma}}$ peptides quantifier and sequencer. 


\section{Determination of isoelectric point and amino acids composition top 20 unique proteins in each group}

The isoelectric point and amount of the amino acid in the top 20 proteins identified in each of the control and the treatment group was determined using a web-based isoelectric point calculator [16].

\section{Statistical and bioinformatics analysis}

The uniprot_rabbit_2019 database was used for the protein sequence identification; parameters including a fragment mass tolerance of $0.6 \mathrm{Da}$ with a false discovery rate (FDR) of $1 \%$ at the significance threshold of $p<0.004$ was used for the taxonomy of the proteins sequences while all possible entries of the amino acid sequence were accepted. The data obtained for oxidative stress biomarkers of the liver and serum samples were subjected to the Mann-Whitney $U$ test at $p<0.05$ for determining the differences between the oxidative stress biomarkers in the liver and serum of the rabbit due to the intake of the Chlorella vulgaris. For the functional enrichment, processes, and pathways analyses, the hepatic proteome data obtained were analyzed using the STRING database, g:profiler, and Cytoscape [17].

\section{Results}

\section{Liver and serum oxidative stress status of the rabbits}

There was a significant difference in oxidative stress status of the rabbits' liver and serum. The concentration of the liver lipid peroxidation biomarker malondialdehyde was $10.62 \pm 6.20 \mathrm{nmol} / \mathrm{g}$ of the liver sample $(p<0.05)$, while the minimum and maximum lipid peroxidation biomarkers were 1.03 and $19.65 \mathrm{nmol} / \mathrm{g}$ of the liver sample, respectively. There was also a significant difference in the total antioxidant capacity, protein carbonyl content, activities of the superoxide dismutase, and the concentration of glutathione in the liver of the rabbits. The concentration of glutathione was $9.49 \pm 2.39 \mathrm{mmol} / \mathrm{g}$ of the liver samples $(p<0.05)$. The supplemented rabbits had lower oxidative stress status (Figs. 1 and 2).

\section{Liver proteome and protein abundance}

In total, there was an identification of 544 proteins, and out of these proteins, 204 proteins were unique to the control group, 198 proteins were unique to the treatment group, while 142 proteins were common to both the control and treatment groups. The control group made up of $2,100,10$, and 234 predicted, uncharacterized, LOC, and known proteins, respectively. Similarly, the treatment group comprised of 2, 106, 2, and 230 predicted, uncharacterized, LOC, and known proteins, respectively (Fig. 3). The topmost unique proteins in each of the groups indicated similar physicochemical features (Tables 1 and 2).

\section{Functional enrichment of the upregulated antioxidant proteins}

Antioxidant proteins including SOD1, SOD2, catalase (CAT), DHRS4, PRDX3, macrophage migration inhibitory factor (MIF), HSPD1, ALB, and glutathione Stransferase Pi 1 (GSTP1) were found in both groups but they were significantly upregulated in the treatment group compared with the control group (Fig. 4). The enrichment of these proteins revealed their involvement in biological processes and pathways relevant to oxidative stress protection as detailed in (Supplementary Table 1). Elucidation of the upregulated antioxidant proteins with a specific focus on

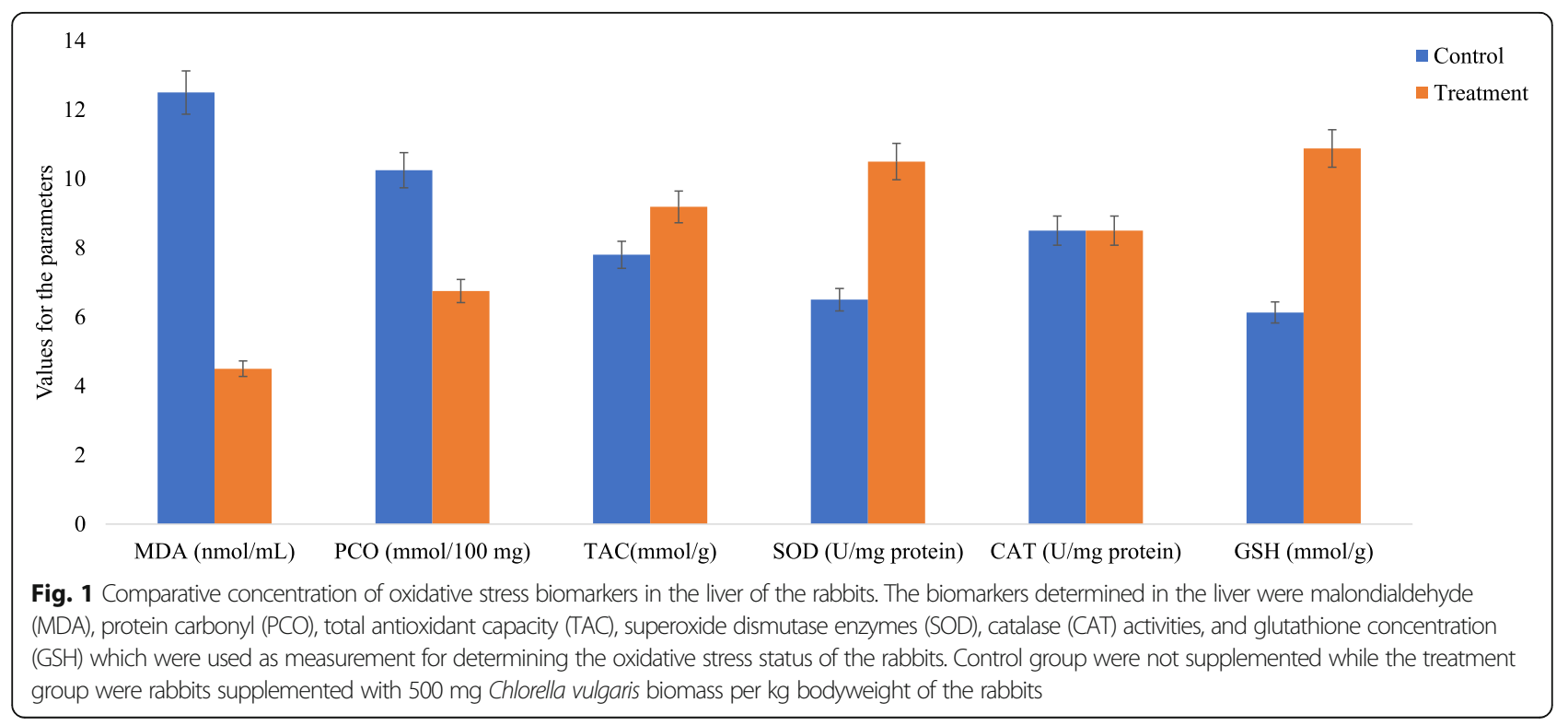




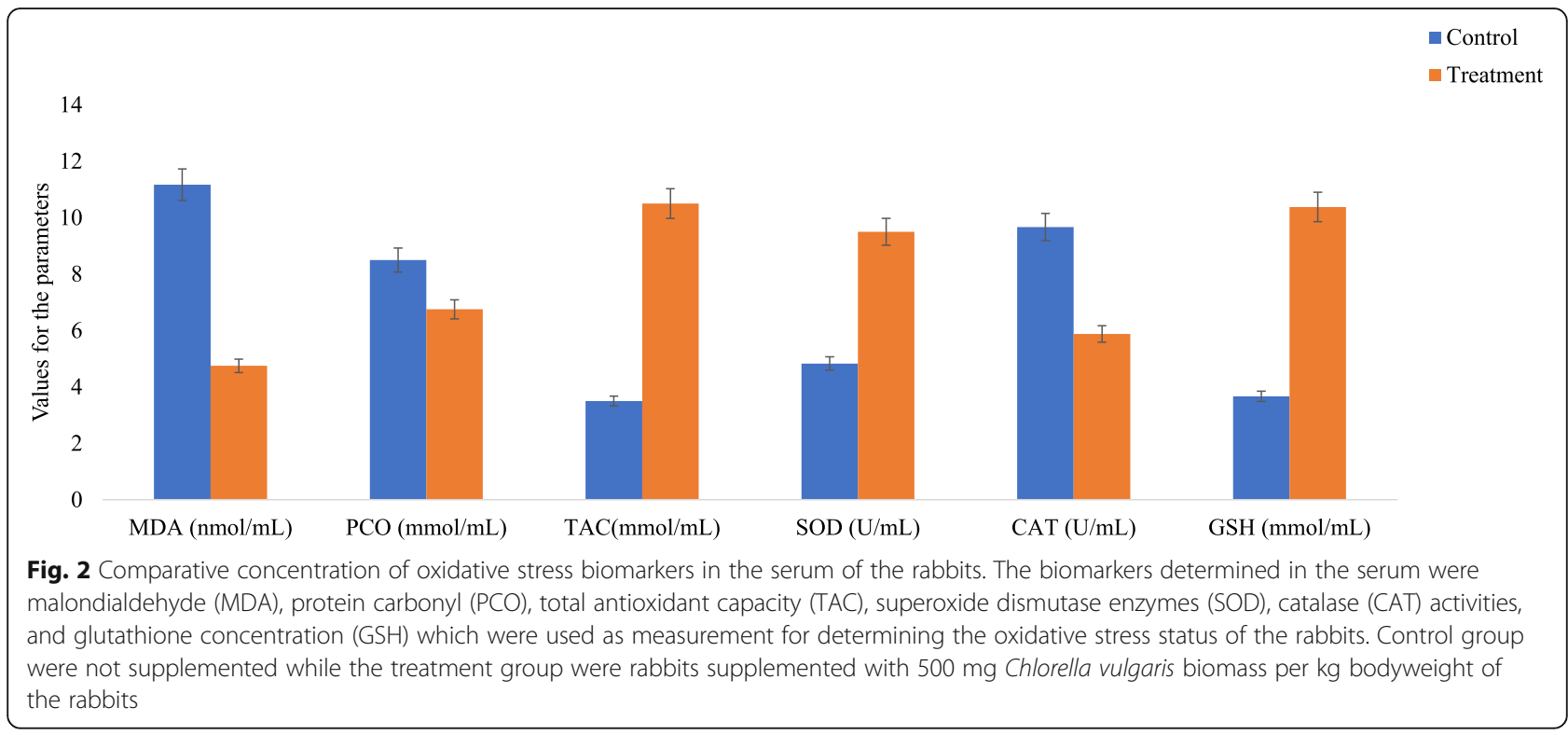

their roles in oxidative stress indicated that the proteins are involved in oxidoreductase activities, antioxidant protection by decomposing of hydrogen peroxide, and response to interleukin-12 complications (Fig. 5).

\section{Discussion}

In this present study, the effect of Chlorella vulgaris supplementation on protein expression in connection with liver oxidative stress of rabbits was investigated. It is necessary to understand this because oxidative stress is a

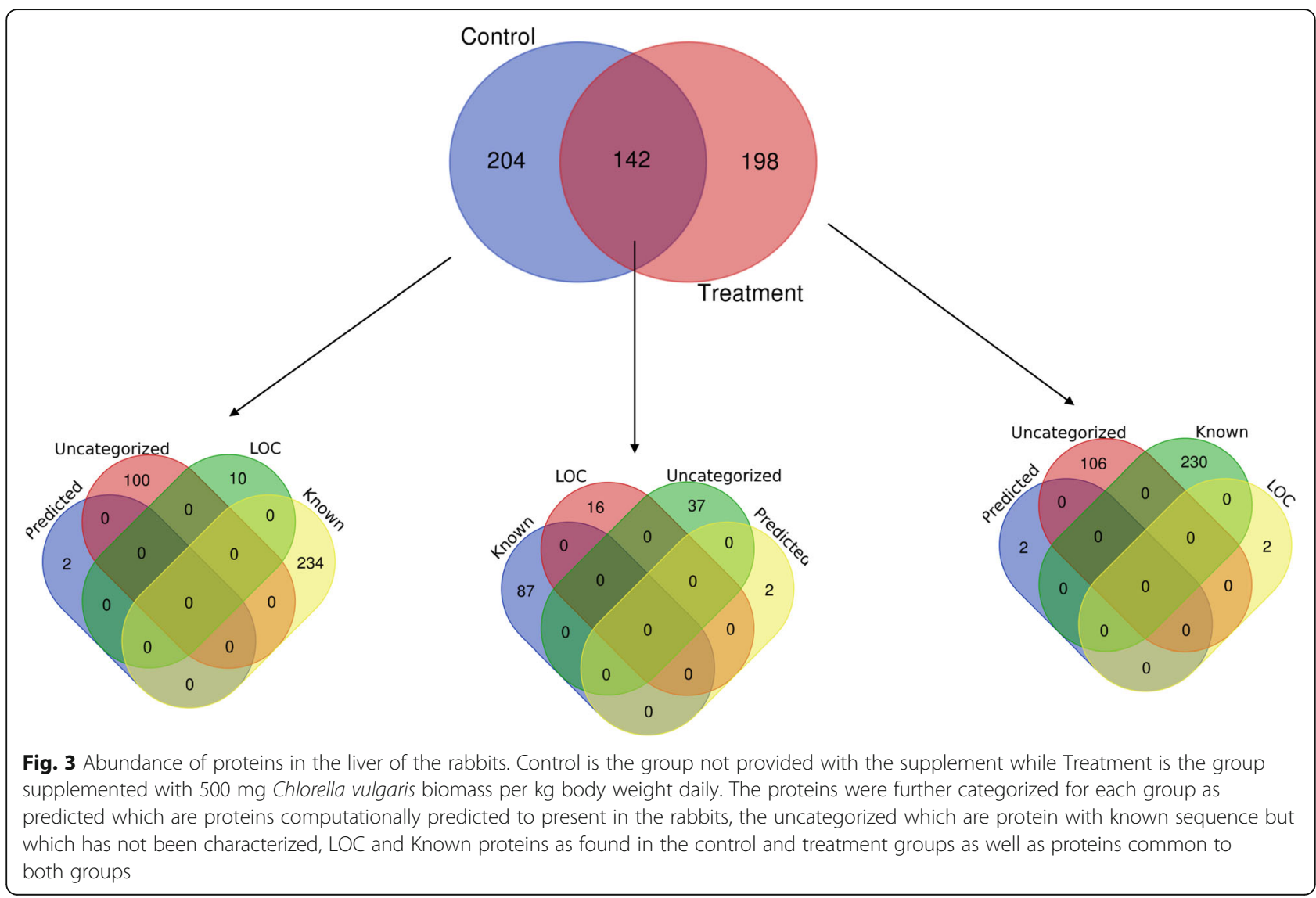


Table 1 List and physicochemical properties of topmost abundant proteins in the liver proteome of the rabbits in the control group

\begin{tabular}{|c|c|c|c|c|c|c|}
\hline & Accession & Description & Mass (KDa) & Score & $\mathrm{pl}$ & No of amino acids \\
\hline 1 & B8K174 & Hemoglobin, beta (Predicted) & 16.18 & 2141 & 7.67 & 147 \\
\hline 2 & B8K132 & Alpha-hemoglobin (Predicted) & 15.65 & 1042 & 7.68 & 142 \\
\hline 3 & G1TEA7 & Uncharacterized protein & 166.64 & 1017 & 5.89 & 1479 \\
\hline 4 & P12337 & Liver carboxylesterase 1 & 62.59 & 912 & 5.92 & 565 \\
\hline 5 & G1SRL5 & Carboxylic ester hydrolase & 62.43 & 884 & 5.99 & 579 \\
\hline 6 & Q08862 & Glutathione S-transferase Yc & 25.55 & 665 & 7.91 & 221 \\
\hline 7 & Q08863 & Glutathione S-transferase alpha I & 25.73 & 485 & 8.22 & 223 \\
\hline 8 & G1T4A7 & Uncharacterized protein & 29.40 & 337 & 6.02 & 257 \\
\hline 9 & G1T2B1 & Uncharacterized protein & 25.56 & 320 & 8.53 & 221 \\
\hline 10 & G1T2A7 & Uncharacterized protein & 25.46 & 295 & 8.33 & 225 \\
\hline 11 & U3KNH6 & Uncharacterized protein & 16.56 & 281 & 7.85 & 221 \\
\hline 12 & Q03505 & Alcohol dehydrogenase 1 & 40.36 & 267 & 7.46 & 375 \\
\hline 13 & G1T295 & Epoxide hydrolase & 52.72 & 260 & 6.68 & 455 \\
\hline 14 & Q8Ml17 & Retinal dehydrogenase 1 & 54.93 & 240 & 6.51 & 496 \\
\hline 15 & G1SUY2 & Aldedh domain-containing protein & 54.83 & 219 & 6.14 & 521 \\
\hline 16 & G1T6W7 & Catalase & 59.91 & 199 & 6.69 & 527 \\
\hline 17 & G1SL62 & Annexin & 39.58 & 193 & 7.46 & 342 \\
\hline 18 & G1SKJ7 & Glycine N-methyltransferase & 33.30 & 185 & 6.66 & 295 \\
\hline 19 & G1SNT8 & Annexin & 89.35 & 181 & 5.37 & 786 \\
\hline 20 & P00179 & Cytochrome P450 2C5 & 55.92 & 179 & 6.24 & 487 \\
\hline
\end{tabular}

Table 2 List and physicochemical properties of topmost abundant proteins in the liver proteome of the rabbits in the treatment

\begin{tabular}{|c|c|c|c|c|c|c|}
\hline & Accession & Description & Mass (KDa) & Score & $\mathrm{pl}$ & No of amino acids \\
\hline 1 & B8K174 & Hemoglobin, beta (Predicted) & 16.18 & 2804 & 7.67 & 147 \\
\hline 2 & B8K132 & Alpha-hemoglobin (Predicted) & 15.65 & 777 & 7.68 & 142 \\
\hline 3 & G1U9S2 & Serum albumin & 70.92 & 293 & 5.63 & 608 \\
\hline 4 & QOQEN9 & ATP synthase subunit beta (Fragment) & 45.55 & 254 & 5.09 & 422 \\
\hline 5 & G1SL06 & Actin, alpha skeletal muscle & 42.37 & 248 & 5.03 & 369 \\
\hline 6 & G1SJS1 & Histone $\mathrm{H} 2 \mathrm{~B}$ & 13.91 & 248 & 9.76 & 126 \\
\hline 7 & G1T6W7 & Catalase & 59.91 & 217 & 6.69 & 527 \\
\hline 8 & P15541 & Aminopeptidase N & 109.65 & 195 & 5.06 & 966 \\
\hline 9 & G1T346 & Uncharacterized protein & 290.20 & 194 & 5.12 & 2541 \\
\hline 10 & G1T3Y8 & Uncharacterized protein & 56.80 & 185 & 5.58 & 573 \\
\hline 11 & G1SYV9 & Uncharacterized protein & 272.75 & 183 & 5.62 & 2558 \\
\hline 12 & G1SZF7 & Isocitrate dehydrogenase [NADP] & 51.26 & 176 & 7.9 & 452 \\
\hline 13 & G1SFP0 & Cytosol AP domain-containing protein & 56.65 & 175 & 7.74 & 519 \\
\hline 14 & P79226 & Fructose-bisphosphate aldolase B & 40.04 & 173 & 7.45 & 364 \\
\hline 15 & P00883 & Fructose-bisphosphate aldolase A & 39.77 & 170 & 7.29 & 364 \\
\hline 16 & G1SL62 & Annexin & 39.58 & 167 & 7.46 & 342 \\
\hline 17 & G1SDD0 & Uncharacterized protein & 31.53 & 157 & 7.74 & 280 \\
\hline 18 & G1SXX5 & Uncharacterized protein & 83.21 & 155 & 8.51 & 797 \\
\hline 19 & G1SKT4 & ATP synthase subunit alpha & 59.83 & 153 & 8.43 & 553 \\
\hline 20 & Q9GKX2 & Dehydrogenase/reductase SDR family member 4 (Fragment) & 27.64 & 152 & 7.71 & 260 \\
\hline
\end{tabular}




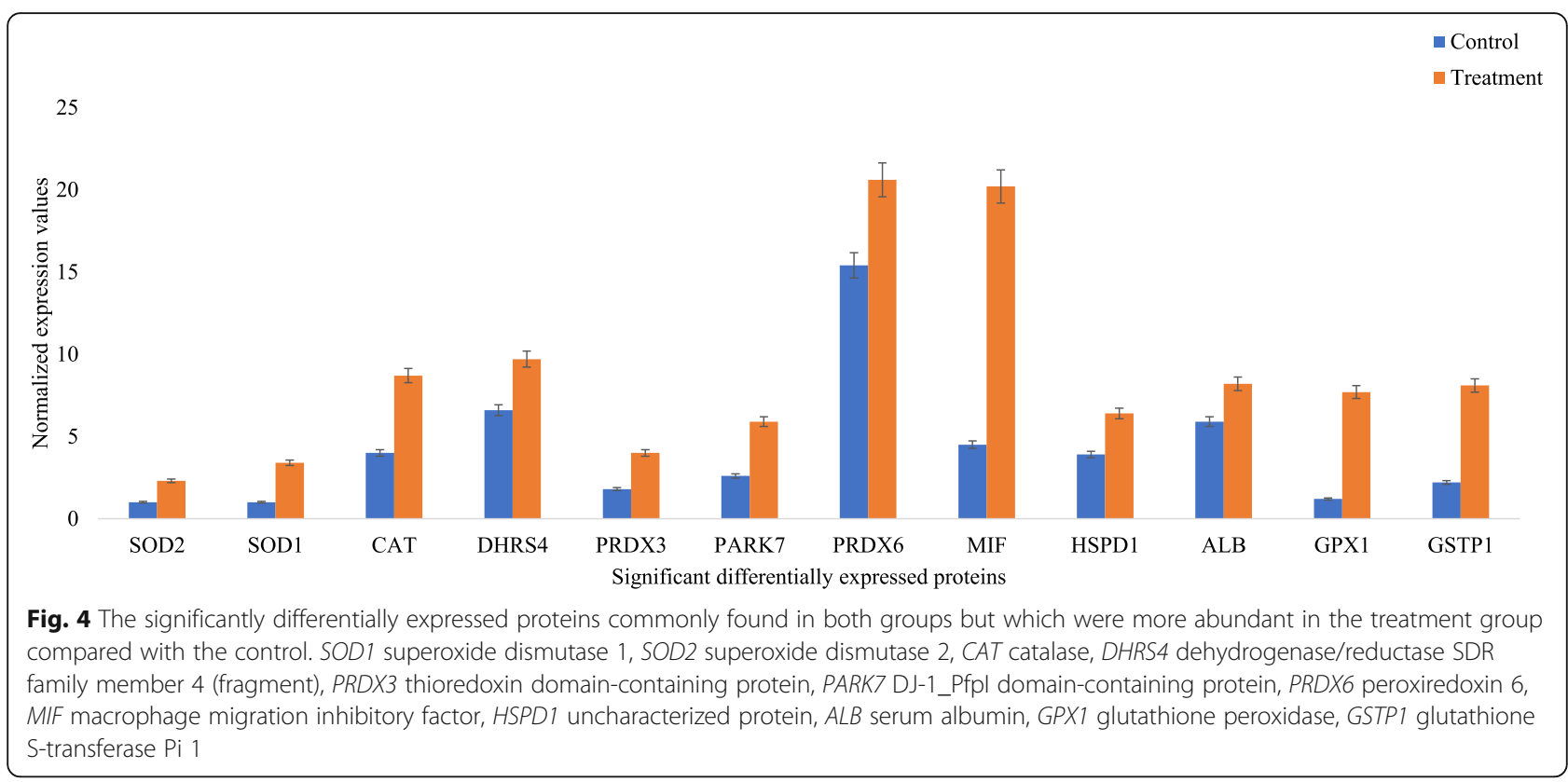

biochemical process causing the generation of reactive oxygen species, molecules, and or ions formed through incomplete electron reduction reaction of oxygen and this is strongly involved in pathways affecting normal cellular functions of the liver. Oxidative stress is a critical factor responsible for the progression of liver and non-liver dysfunctional conditions such as non-alcoholic fatty liver diseases (NAFLD), male infertility, pulmonary carcinogenesis, hypoxia, and vascular malfunctions [1822]. However, despite the ubiquitous nature of oxidative stress, the supplementation of antioxidants have been widely reported as a way-out of its complications but the exact mechanisms underlying efficacies of some of the antioxidants in oxidative stress protection in-vivo is poorly understood [23].

Although, reports from recent investigations on antioxidant agent supplementation identified that gene expression and regulation modification for cellular protection against oxidative stress in rabbits and other models are mechanisms associated with intakes of antioxidant agents including microalgae [24, 25]. Therefore, in taking a step further, this present study confirmed some of the assertions by indicating that antioxidant agents could have some post-transcription modulation impacts against oxidative stress because the supplementation of Chlorella vulgaris in this study led to a higher antioxidant proteins expression in the liver of the supplemented rabbits. The outcome of this present study also showed that primary antioxidant enzymes such as superoxide dismutase, catalase, and glutathione could be active across the cytoplasmic and mitochondria phases of oxidative stress protections since observations recorded showed that the proteins are more in the treatment group versus the control. Meanwhile, this is in agreement with a previous report which stated that the increasing abundance of antioxidant proteins could be associated with the effectiveness of cytosolic and mitochondria oxidative stress protection in cells [26].

Furthermore, functional enrichment of the proteins upregulated in the supplemented rabbits indicated that in association with other proteins, they are involved in the scavenging of free radicals and their upregulation is required for reduced oxidative stress. This observation could be accepted as a confirmation that the microalga Chlorella vulgaris is a potential drug and nutraceutical candidate since the biological processes and pathways analysis of the proteome indicated that the supplementation of the microalga modulated cellular response of the liver to inhibit cellular oxidative stress damage basically via the hydrogen peroxide metabolism and detoxification of xenobiotics compounds. These cellular activities can be linked to prominent mechanisms involving catalytic removal of free radicals by superoxide dismutase, catalase, and peroxidase, and scavenging of reactive species by low molecular agents such as carotenoids present in the microalga Chlorella vulgaris [27].

The superoxide dismutase proteins were more abundant in the supplemented rabbits, and this could be regarded as the starting point of endogenous antioxidant protection mechanism whereby one superoxide radical is oxidized and the second one is reduced to eliminate continuous damage by radical oxygen. Although this mechanism usually leads to the production of hydrogen peroxide which is another reactive compound, the hydrogen peroxide produced is usually quickly acted upon by subsequent enzymatic actions. The catalase and 


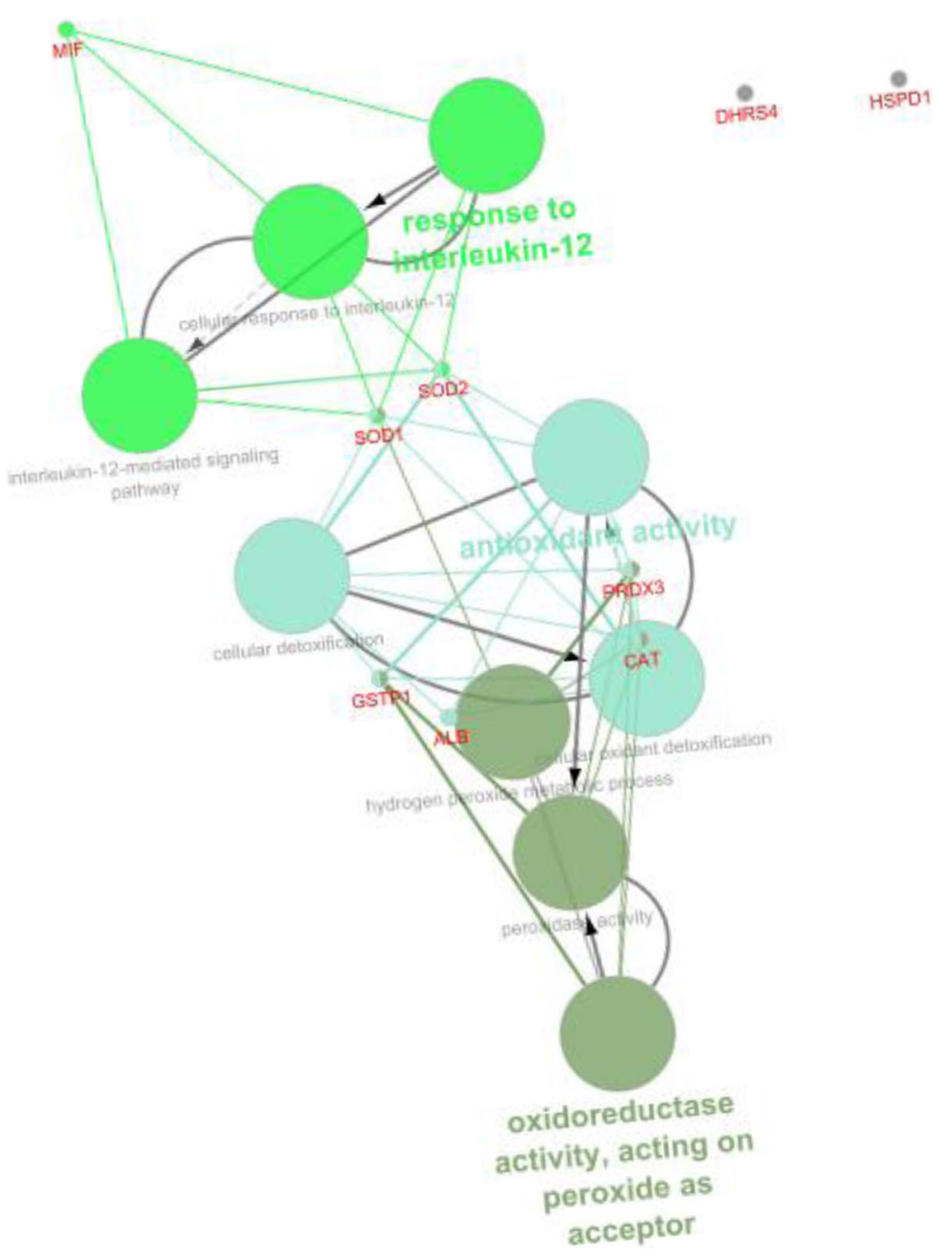

Fig. 5 Pathway analysis of the inter-protein interactions of the differentially expressed proteins associated with oxidative stress protection in the liver of the supplemented rabbits using Cluego App of the Cytoscape 8.3.1. The pathway analysis showed that the specific oxidative stress protection were the functions of these proteins where they function in oxidoreductase activity, acting on peroxide as acceptor, intracellular antioxidant activity, cellular oxidant detoxification, hydrogen peroxide metabolic process, cellular detoxification, interleukin-12 mediated pathways and response to interleukin-12. The supplemented group were provided with $500 \mathrm{mg}$ Chlorella vulgaris biomass per kg body weight daily throughout the experimental period

glutathione peroxidases carry out further actions in the cytoplasm while in the mitochondria glutathione reductase carry out the inhibition of the free radical activities; these observations agreed with submissions of [27].

The inter-protein interactions and functional enrichment analyses in this present study indicated that the supplementation of Chlorella vulgaris biomass as an antioxidant in rabbit led to increased activities of the antioxidant enzymes activities and increased production of their respective proteins to prevent liver oxidative stress damages and progression in a mechanism similar to impacts of ascorbate which is a common conventional antioxidant agent. In agreement with this submission, Halliwell and Gutteridge [28] suggested that antioxidant agent supplements are expected to exhibit the capability of enhancing both enzymatic and non-enzymatic antioxidant activities. In upholding this submission, this present study demonstrated that the intake of the microalga increases the antioxidant enzymes activities and their respective proteins including the catalase (CAT), peroxiredoxin (PRDX6), macrophage migration inhibitory factor (MIF), and glutathione S-transferase $\mathrm{Pi} 1$ (GSTP1) due to their higher abundance in the supplemented group compared with the control group.

The reduction of the lipid peroxidation biomarker malondialdehyde in the liver of the supplemented rabbits could be linked with the increased expression of the antioxidant proteins because of the microalga intakes and this can be described as a mechanism of oxidative stress protection in the liver promoted by the microalga. In specific, the higher expression of the catalase protein could be primarily linked with the protection of cells 
against the toxic effects of hydrogen peroxide as well as promoting the growth of immune cells including $\mathrm{T}$ cells and B cells; and hence, this could be described as double effects of oxidative stress protection and immune enhancement. This observation is in agreement with [29], which stated that antioxidant therapy focusing on reducing oxidative stress and enhancing activities of $\mathrm{T}$ cells and $\mathrm{B}$ cells could also lead to immune protection against oxidative stress-mediated diseases such as organ damage and comorbidities in systemic lupus erythematosus (SLE).

Similarly, increased expression of peroxiredoxin (PRDX6) in the supplemented rabbit affirm competency of the microalga supplemented to protect against oxidative stress. This is because as a protein-encoded gene and a member of the thiol-specific antioxidant protein family, it has a bifunctional enzyme with two distinct active sites involved in redox regulation of the cell [30]. The increased expression of peroxiredoxin in the supplement rabbits can reduce pro-oxidant activities of hydrogen peroxide and short-chain organic, fatty acid, and phospholipid hydroperoxides and it may also play a role in the regulation of phospholipid turnover as well as in protection against oxidative injury [7]. The microalga supplementation also increased MIF which indicates that it is a potent antioxidant agent since the gene MIF encodes a lymphokine involved in cell-mediated immunity, immunoregulation, and inflammation which plays roles in the regulation of macrophage function in host defense through the suppression of anti-inflammatory effects of glucocorticoids - a mechanism substantial for protection against environmental triggered stress at the cellular level [31].

In correlating the malondialdehyde concentration reduction with the increasing abundance of antioxidant proteins in the supplemented rabbits as observed in this study, it could be juxtaposed that supplementation of the microalga Chlorella vulgaris prevented attacks on lipid signaling and also led to the upregulation of its associated proteins as well as enhanced activities of the antioxidant enzymes. These submissions agreed with [32], which opined that under normal physiological conditions, there will be reduced malondialdehyde concentrations necessary for cellular stimulation, maintenance, and survival occurring through activities of antioxidant enzymes and antioxidant genes for promoting the constitutive antioxidants defense systems and protection of lipid signaling pathways as well as activation of genes expression required for upregulating antioxidants proteins needed for the formation of adequate protection and adaptation to the stress response. The underlying physiological importance of reduced malondialdehyde in association with the antioxidant protein abundance in the liver could therefore be described as critical for the promotion of healthy living. This is because if otherwise, the cells can induce inordinate apoptosis or necrosis resulting in cell deaths and facilitation of various pathological conditions [33].

The mechanism of oxidative stress promotion of liver diseases involves the activation of stellate cells by the free radicals leading to the synthesis of collagen and the extracellular matrix [34]. These are complications associated with liver diseases such as non-alcoholic fatty liver diseases, fibrosis, and encephalopathy. This present study suggests that Chlorella vulgaris could serve as an antioxidant supplement suitable for the alleviation of these liver diseases. This is in agreement with a report that the microalga improved liver health through the modulation of the fasting blood sugar and lipid profile in a double-blind randomized placebo-controlled clinical trial involving 60 NAFLD patients [35, 36]. Furthermore, the present study demonstrated a possible molecular basis for the effectiveness of the microalga as an antioxidant agent suitable for the management of liver damages because of the inter-protein interaction of the significantly upregulated antioxidant proteins in the supplemented group which revealed the involvement of the proteins in more than a hundred pathways associated with oxidative stress-protective activities (Supplementary Table 1).

\section{Conclusion}

This present study in its novelty contributed that liver is an organ vulnerable to oxidative stress damages which could be a critical promoter of acute and or chronic liver diseases. The microalga Chlorella vulgaris is a potential candidate for antioxidant drugs that could be effectively used to reduce liver oxidative stress because it reduces the generation of oxidative stress products, enhances the activities of antioxidant enzymes, and promote the upregulation of antioxidant proteins in the liver.

\section{Abbreviations}

ICAR: Indian Council for Agricultural Research; NIANP: National Institute of Animal Nutrition and Physiology; NAFLD: Non-alcoholic fatty liver diseases; IAEC: Institutional Animal Ethics Committee; CPCSEA: Committee for Control and Supervision on Experiments on Animals:

RIPA: Radioimmunoprecipitation assay; SDS: Sodium dodecyl sulfate; DTT: Dithiothreitol; IAA: lodoacetamide; LC-MS: Liquid chromatography-mass spectrometry; HPLC: High-performance liquid chromatography; FDR: False discovery rate; CAT: Catalase; PRDX6: Peroxiredoxin; MIF: Macrophage migration inhibitory factor; GSTP1: Glutathione S-transferase Pi 1; SOD: Superoxide dismutase

\section{Supplementary Information}

The online version contains supplementary material available at https://doi. org/10.1186/s43066-021-00118-3.

Additional file 1. Supplementary Table 1.

Additional file 2. Protein Abundance. 


\section{Acknowledgements}

The authors sincerely appreciate the support of the Indian Council for Agricultural Research (ICAR) and Director, ICAR-National Institute of Animal Nutrition and Physiology, Bengaluru; India for providing facilities used for conducting this research. Special thanks to the Department of Biotechnology (DBT) and The World Academy of Sciences (TWAS), Italy for awarding PhD fellowship to $S A B$ and provision of grants for the research. The authors also appreciate the Centre for Cellular and Molecular Platforms (C-CAMP), Bengaluru, India, for providing facilities used for the protein profiling and analysis of the LC-MS results.

\section{Availability of data and material}

All data were reported in the manuscript and additional data are presented as supplementary materials.

\section{Consent for publications}

Not applicable.

\section{Declarations}

\section{Authors' contributions}

Conceptualization: SAB, AA. Data curation: SAB, AA. Formal analysis: SAB. Methodology: SAB, AA. Software: AA. Validation: AA, ESSA, IJR, SV, RB. Investigation: $S A B$. Writing —original draft: $S A B$. Writing - review and editing: AA, ESSA, IJR, SV, RB. All authors have read and approved the manuscript for submission.

\section{Funding}

The World Academy of Sciences (TWAS), Italy and the Department of Biotechnology (DBT), India jointly awarded PhD fellowship to SAB, and also provided grants which was used for carrying out the experimental studies.

\section{Ethics approval and consent to participate}

Approval for use of the animals and the implementation of the experimental protocols were obtained from a joint sitting of the Institutional Animal Ethics Committee (IAEC) of National Institute of Animal Nutrition and Physiology, India, and the Committee for Control and Supervision on Experiments on Animals (CPCSEA), India. The approval reference number is $141437 / \mathrm{GO} / \mathrm{Re} /$ SL/11/CPCSEA Dt.8.12.2017 Valid up to 7.12.2022.

\section{Competing interests}

The authors declare that they have no competing interests.

\section{Author details}

'Department of Animal Production, Federal University of Technology, Minna 920262, Nigeria. ${ }^{2}$ Reproductive Physiology Laboratory, ICAR-National Institute of Animal Nutrition and Physiology, Bangalore 560030, India. ${ }^{3}$ Animal Physiology Division, ICAR-National Institute of Animal Nutrition and Physiology, Bangalore 560030, India. ${ }^{4}$ ICAR-National Institute of Animal Nutrition and Physiology, Bangalore 560030, India.

\section{Received: 4 February 2021 Accepted: 2 June 2021}

\section{Published online: 12 June 2021}

\section{References}

1. Li S, Tan H-Y, Wang N, Zhang Z-J, Lao L, Wong C-W, Feng Y (2015) The role of oxidative stress and antioxidants in liver diseases. Int J Mol Sci 16(11): 26087-26124. https://doi.org/10.3390/ijms161125942

2. Farzaei M, Zobeiri M, Parvizi F, El-Senduny F, Marmouzi I, Coy-Barrera E et al (2018) Curcumin in liver diseases: a systematic review of the cellular mechanisms of oxidative stress and clinical perspective. Nutrients 10(7):855. https://doi.org/10.3390/nu10070855

3. Agarwal A, Roychoudhury S, Bjugstad KB, Cho C-L (2016) Oxidationreduction potential of semen: what is its role in the treatment of male infertility? Ther Adv Urol 8(5):302-318. https://doi.org/10.1177/175628721 6652779

4. Christaki E, Karatzia M, Florou-Paneri P (2010) The use of algae in animal nutrition. J Hell Vet Med Soc 61:267-276

5. Sikiru AB, Arangasamy A, Alemede IC, Guvvala PR, Egena SSA, Ippala JR, Bhatta R (2019) Chlorella vulgaris supplementation effects on performances, oxidative stress and antioxidant genes expression in liver and ovaries of New Zealand White rabbits. Heliyon 5(9):e02470. https://doi.org/10.1016/j. heliyon.2019.e02470

6. Kausar S, Wang F, Cui H (2018) The role of mitochondria in reactive oxygen species generation and its implications for neurodegenerative diseases. Cells 7(12):274. https://doi.org/10.3390/cells7120274

7. Fujii J, Ikeda Y (2002) Advances in our understanding of peroxiredoxin, a multifunctional, mammalian redox protein. Redox Rep 7(3):123-130. https:// doi.org/10.1179/135100002125000352

8. Asrani SK, Devarbhavi H, Eaton J, Kamath PS (2019) Burden of liver diseases in the world. J Hepatol 70(1):151-171. https://doi.org/10.1016/j.jhep.2018.09.014

9. Hong M, Li S, Tan H, Wang N, Tsao S-W, Feng Y (2015) Current status of herbal medicines in chronic liver disease therapy: the biological effects, molecular targets and future prospects. Int J Mol Sci 16(12):28705-28745. https://doi.org/10.3390/ijms161226126

10. Sikiru A, Arangasamy A, Alemede I, Egena S, Ippala J, Bhatta R (2021) Effects of dietary supplementation of Chlorella vulgaris on oxidative stress attenuation and serum biochemical profile of pregnant New Zealand White rabbits. Indian J Anim Sci 90:88-91

11. Sikiru AB, Arangasamy A, Alemede IC, Egena SSA, Bhatta R (2019) Dietary supplementation effects of Chlorella vulgaris on performances, oxidative stress status and antioxidant enzymes activities of prepubertal New Zealand White rabbits. Bull Natl Res Cent 43(1). https://doi.org/10.1186/s42269-0190213-8

12. Sikiru A, Arangasamy A, ljaiya A, Ippala R, Bhatta R (2019) Effects of Chlorella vulgaris supplementation on performances of lactating nulliparous New Zealand white rabbits does and their kits. Int I Livest Res 1. https://doi.org/1 0.5455/ijlr.20190626094302

13. Pike TW, Blount JD, Metcalfe NB, Lindström J (2010) Dietary carotenoid availability and reproductive effort influence the age-related decline in performance. Behav Ecol 21(5):1048-1053. https://doi.org/10.1093/beheco/a rq102

14. Kurutas EB (2015) The importance of antioxidants which play the role in cellular response against oxidative/nitrosative stress: current state. Nutr J 15(1):71. https://doi.org/10.1186/s12937-016-0186-5

15. Butterfield D, Perluigi M (2017) Redox proteomics: a key tool for new insights into protein modification with relevance to disease

16. Kozlowski LP (2016) IPC - Isoelectric Point Calculator. Biol Direct 11(1):55. https://doi.org/10.1186/s13062-016-0159-9

17. Raudvere U, Kolberg L, Kuzmin I, Arak T, Adler P, Peterson H et al (2019) g: Profiler: a web server for functional enrichment analysis and conversions of gene lists. Nucleic Acids Res 47:191-198

18. Kalyanaraman B, Cheng G, Hardy M, Ouari O, Bennett B, Zielonka J (2018) Teaching the basics of reactive oxygen species and their relevance to cancer biology: mitochondrial reactive oxygen species detection, redox signaling, and targeted therapies. Redox Biol 15:347-362. https://doi.org/1 0.1016/j.redox.2017.12.012

19. Mennerich D, Kellokumpu S, Kietzmann T (2019) Hypoxia and reactive oxygen species as modulators of endoplasmic reticulum and golgi homeostasis. Antioxid Redox Signal 30(1):113-137. https://doi.org/10.1089/a rs.2018.7523

20. Baker MA, Netherton J, Aitken RJ (2019) From past to present. oxid. Antioxidants impact Oxidative Status Male Reprod. Elsevier, pp 17-26. https://doi.org/10.1016/B978-0-12-812501-4.00003-1

21. Tejero J, Shiva S, Gladwin MT (2019) Sources of vascular nitric oxide and reactive oxygen species and their regulation. Physiol Rev 99(1):311-379. https://doi.org/10.1152/physrev.00036.2017

22. Valavanidis A (2019) Oxidative stress and pulmonary carcinogenesis through mechanisms of reactive oxygen species. How respirable particulate matter, fibrous dusts, and ozone cause pulmonary inflammation and initiate lung carcinogenesis. In: Oxidative Stress Lung Dis. Springer Singapore, Singapore, pp 247-265. https://doi.org/10.1007/978-981-13-8413-4_13

23. Han E-S, Muller FL, Pérez VI, Qi W, Liang H, Xi L, Fu C, Doyle E, Hickey M, Cornell J, Epstein CJ, Roberts LJ, van Remmen H, Richardson A (2008) The in vivo gene expression signature of oxidative stress. Physiol Genomics 34(1):112-126. https://doi.org/10.1152/physiolgenomics.00239.2 007

24. Ahmed AA, Fedail JS, Musa HH, Musa TH, Sifaldin AZ (2016) Gum Arabic supplementation improved antioxidant status and alters expression of oxidative stress gene in ovary of mice fed high fat diet. Middle East Fertil Soc J 21(2):101-108. https://doi.org/10.1016/j.mefs.2015.10.001 
25. Dornas WC, Cardoso LM, Silva M, Machado NLS, Chianca DA, Alzamora AC Lima WG, Lagente V, Silva ME (2017) Oxidative stress causes hypertension and activation of nuclear factor-kB after high-fructose and salt treatments. Sci Rep 7(1):46051. https://doi.org/10.1038/srep46051

26. Song $X$, Narzt MS, Nagelreiter IM, Hohensinner P, Terlecki-Zaniewicz L, Tschachler E, Grillari J, Gruber F (2017) Autophagy deficient keratinocytes display increased DNA damage, senescence and aberrant lipid composition after oxidative stress in vitro and in vivo. Redox Biol 11:219-230. https://doi. org/10.1016/j.redox.2016.12.015

27. Barber S, Mead R, Shaw P (2006) Oxidative stress in ALS: a mechanism of neurodegeneration and a therapeutic target. Biochim Biophys Acta (BBA)Molecular Basis Dis 1762:1051-1067

28. Halliwell B, Gutteridge J (2015) Free radicals in biology and medicine. https://doi.org/10.1093/acprof:oso/9780198717478.001.0001

29. Perl A (2013) Oxidative stress in the pathology and treatment of systemic lupus erythematosus. Nat Rev Rheumatol 9(11):674-686. https://doi.org/10.1 038/nrrheum.2013.147

30. Manevich Y, Fisher A (2005) Peroxiredoxin 6, a 1-Cys peroxiredoxin, functions in antioxidant defense and lung phospholipid metabolism. Free Radic Biol Med 38(11):1422-1432. https://doi.org/10.1016/j.freeradbiomed.2 005.02.011

31. Park M (2018) Dissecting the impact of macrophage migration inhibitory factor (MIF) on host immune response

32. Ayala A, Muñoz M, Argüelles S (2014) Lipid peroxidation: production, metabolism, and signaling mechanisms of malondialdehyde and 4-hydroxy2-nonenal. Oxidative Med Cell Longev 2014:1-31. https://doi.org/10.1155/2 $014 / 360438$

33. Gudipaty S, Conner C, Rosenblatt J, Montell D (2018) Unconventional ways to live and die: cell death and survival in development, homeostasis, and disease. Annu Rev Cell Dev Biol 34(1):311-332. https://doi.org/10.1146/a nnurev-cellbio-100616-060748

34. Ramos-Tovar E, Muriel P (2020) Molecular mechanisms that link oxidative stress, inflammation, and fibrosis in the liver. Antioxidants 9(12):1279. https://doi.org/10.3390/antiox9121279

35. Ebrahimi-Mameghani M, Aliashrafi S, Javadzadeh Y, AsghariJafarabadi M (2014) The effect of chlorella vulgaris supplementation on liver en-zymes, serum glucose and lipid profile in patients with non-alcoholic fatty liver disease. Health Promot Perspect 4(1):107-115. https://doi.org/10.5681/hpp.2 014.014

36. Pluchino N, Russo M, Santoro A, Litta P, Cela V, Genazzani A (2013) Steroid hormones and BDNF. Neuroscience 239:271-279. https://doi.org/10.1016/j. neuroscience.2013.01.025

\section{Publisher's Note}

Springer Nature remains neutral with regard to jurisdictional claims in published maps and institutional affiliations.

\section{Submit your manuscript to a SpringerOpen ${ }^{\circ}$ journal and benefit from:}

- Convenient online submission

- Rigorous peer review

- Open access: articles freely available online

- High visibility within the field

- Retaining the copyright to your article

Submit your next manuscript at $\boldsymbol{\nabla}$ springeropen.com 